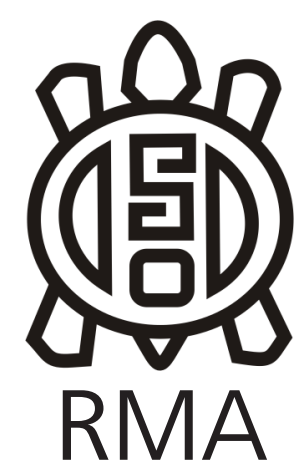

Arqueología

\title{
Entre cuñas, tablillas y escribas: la materialidad de los paisajes funerarios en Mesopotamia durante la Tercera Dinastía de Ur
}

\author{
Between wedges, tablets and scribes: the materiality of the funerary
} landscapes in Mesopotamia during the Third Dynasty of Ur

Rodrigo Cabrera*

* CONICET, Instituto Multidisciplinario de Historia y Ciencias Humanas y Facultad de Filosofía y Letras, Universidad de Buenos Aires, Argentina. E-mail: cabrera.pertusatti@gmail.com

\begin{abstract}
Resumen
El presente trabajo tiene como objetivo el análisis de la espacialidad funeraria durante la Tercera Dinastía de Ur (2110-2003 a.C.) en la Baja Mesopotamia a partir de los postulados teóricos de los llamados estudios sobre la materialidad en Arqueología -los cuales plantean la superación de la dialéctica sujetolobjeto- y también consideraremos la perspectiva semiótica peirciana, que nos permitirá entender cómo las fuentes disponibles (tablillas de arcilla y estructuras de enterramiento) podrían ser abordadas desde una mirada ya no dicotómica, sino triádica. La discusión sobre las tablillas cuneiformes no sólo como portadoras de mensajes -en nuestro caso, textos administrativos- resulta transcendental en la reconstrucción de los paisajes funerarios mesopotámicos. Nos interesa analizar el rol de las denominadas "capillas funerarias" en la reconfiguración administrativa/política durante la Tercera Dinastía de Ur, momento en el que el palacio se apropió de los dispositivos de control de los templos. Asimismo, las capillas funerarias supusieron el fortalecimiento de vínculos entre los muertos de la elite (antepasados), los bienes depositados en su honor (ofrendas funerarias) y el emplazamiento de lugares evocativos. En suma, las capillas funerarias señalaron la realización de prácticas rituales, la cimentación política de la elite palaciega emergente y la monumentalización del paisaje funerario.
\end{abstract}

Palabras clave: Mesopotamia; Tercera Dinastía de Ur; Paisaje funerario; Materialidad; Textos administrativos

\begin{abstract}
The aim of this paper is to analyze the funerary spatiality during the Third Dynasty of Ur (2110-2003 BCE) in Lower Mesopotamia, based on the theoretical postulates of the so-called studies on materiality in Archeology -which propose the overcoming of the subject/object dialectic-and, for that matter, we will also consider the Peircian semiotic perspective, which will allow us to understand how the available sources (clay tablets and burial structures) could be studied from a view that is no longer dichotomous, but triadic. The discussion about the cuneiform tablets not only as carriers of messages -in our case, administrative texts- is transcendental in the reconstruction of Mesopotamian funerary landscapes. We are interested in analyzing the role of the so-called "funeral chapels" in the administrative/political reconfiguration during the Third Dynasty of Ur, at which time the palace appropriated the control mechanisms of the temples. Likewise, the funeral chapels supposed the strengthening of links between the dead of the elite (ancestors), the goods deposited in their honor (funerary offerings), and the location of evocative places. In short, the funeral chapels pointed out the performance of ritual practices, the political foundation of the emerging palace elite, and the monumentalization of the funerary landscape.
\end{abstract}

Keywords: Mesopotamia; Third Dynasty of Ur; Funerary landscape; Materiality; Administrative texts.

En el presente trabajo, proponemos un análisis de las tablillas administrativo-económicas mesopotámicas de la Tercera Dinastía de Ur (de ahora en más Ur III) (Tabla 1), reconociendo las singularidades de los archivos del período. Para ello, discutiremos cómo a partir de la evidencia epigráfica se podría dar cuenta de la (re-) construcción de espacialidades, que, en el marco de la cultura material, todavía no han podido ser reconocidas; en algunos casos, debido a las dificultades que enfrentan las excavaciones arqueológicas en la región.

En tanto tipología textual, la documentación administrativa constituye el mayor corpus de fuentes de la antigua Mesopotamia y más aún si se puntualiza en 


\begin{tabular}{|c|c|c|c|c|}
\hline \multicolumn{4}{|c|}{ Períodos } & CRONOLOGÍA \\
\hline \multirow{4}{*}{\multicolumn{2}{|c|}{$\begin{array}{l}\text { Protodinástico } \\
\text { (PD) }\end{array}$}} & \multicolumn{2}{|r|}{ I } & 2900-2750 a.C. \\
\hline & & \multicolumn{2}{|r|}{ II } & 2750-2600 a.C. \\
\hline & & \multirow[t]{2}{*}{ III } & $a$ & $2600-2500$ a.C. \\
\hline & & & $b$ & 2500-2350 a.C. \\
\hline \multicolumn{4}{|c|}{ Sargónico } & 2350-2200 a.C. \\
\hline \multicolumn{4}{|c|}{ Lagaš II } & 2200-2100 a.C. \\
\hline $\begin{array}{c}\text { Tercera } \\
\text { Dinastía } \\
\text { de Ur }\end{array}$ & \begin{tabular}{l}
\multicolumn{1}{|c}{ Reyes } \\
Ur-Namma (18) \\
Šulgi (48) \\
Amar-Su'ena (9) \\
Šū-Su'en (9) \\
Ibbi-Su'en (24)
\end{tabular} & \multicolumn{2}{|c|}{$\begin{array}{c}\text { Reinado } \\
2110-2093 \text { a.C. } \\
2092-2045 \text { a.C. } \\
2044-2036 \text { a.C. } \\
2035-2027 \text { a.C. } \\
2026-2003 \text { a.C. }\end{array}$} & 2110-2003 a.C. \\
\hline \multicolumn{4}{|c|}{ Paleo-babilónicc } & 2003-1600 a.C. \\
\hline
\end{tabular}

Tabla 1. Cronología de la Baja Mesopotamia durante el tercer milenio y primera mitad del segundo milenio a.C. En gris, se resalta la época de Ur III y los nombres de los monarcas (basado en Sallaberger \& Schrakamp 2015: 131)

Table1. Lower Mesopotamia during the third millenia and second millenia first half $B C$. In grey: Ur III epoch. Monarchs names based on Sallaberger \& Schrakamp 2015:131.

d) fechado de la operación contable (2016: 8). Las tablillas poseían, en su mayoría, entre cinco y quince líneas, y medían entre 4 y $5 \mathrm{~cm}$ de largo/ancho (Molina 2008: 43; Molina 2016: 4).

En esta investigación, a partir de la discusión anterior sobre la estructura morfológica/ sintáctica de las tablillas administrativas de

Ur III. El $90 \%$ de los archivos cuneiformes, con los que contamos para el estudio de los tres milenios de historia mesopotámica, está conformado exclusivamente por textos administrativos, en detrimento de otras tipologías documentales como las inscripciones monumentales/ reales, las lexicográficas y la literatura.

Manuel Molina describe la estructura morfológico/ sintáctica de un texto administrativo (en especial, los de Ur III) del siguiente modo: a) razón de la transacción puesta en absolutivo (objeto a intercambiar con número y medida); b) descripción de la transacción (procedencia, destino, etc.); c) participantes de la transacción en calidad de distribuidores -señalados a través de la locución ki PN-ta, i.e. por medio de una construcción en ablativo-, receptores -marcados con el caso ergativo-y testigos; $y$
Ur III, se analizan las funciones y la respectiva localización del ki-a-naĝ o "capilla mortuoria", en la que se realizaba el ritual funerario y luego se formalizaba el culto mortuorio después del enterramiento del muerto en el ki-mah o "tumba" (Jagersma 2007: 296-297). La mención de la capilla mortuoria en la documentación administrativa del Protodinástico IIIb (PD IIIb) es de 47 veces, mientras que durante Ur III alcanza las 349 entradas (en un total de 233 tablillas) (Tabla 2). Por lo tanto, el ki-a-na operó durante Ur III como la materialización del poder secular encarnado por la monarquía -evidenciada por la preeminencia que adquiere el palacio-, la cual se sirvió de él como base material en su competencia con el templo.

A partir de los datos suministrados por la tabla 2, se

Tablillas administrativas de Ur III con mención del ki-a-naĝ ( $\mathbf{n}=\mathbf{2 3 3}$ )

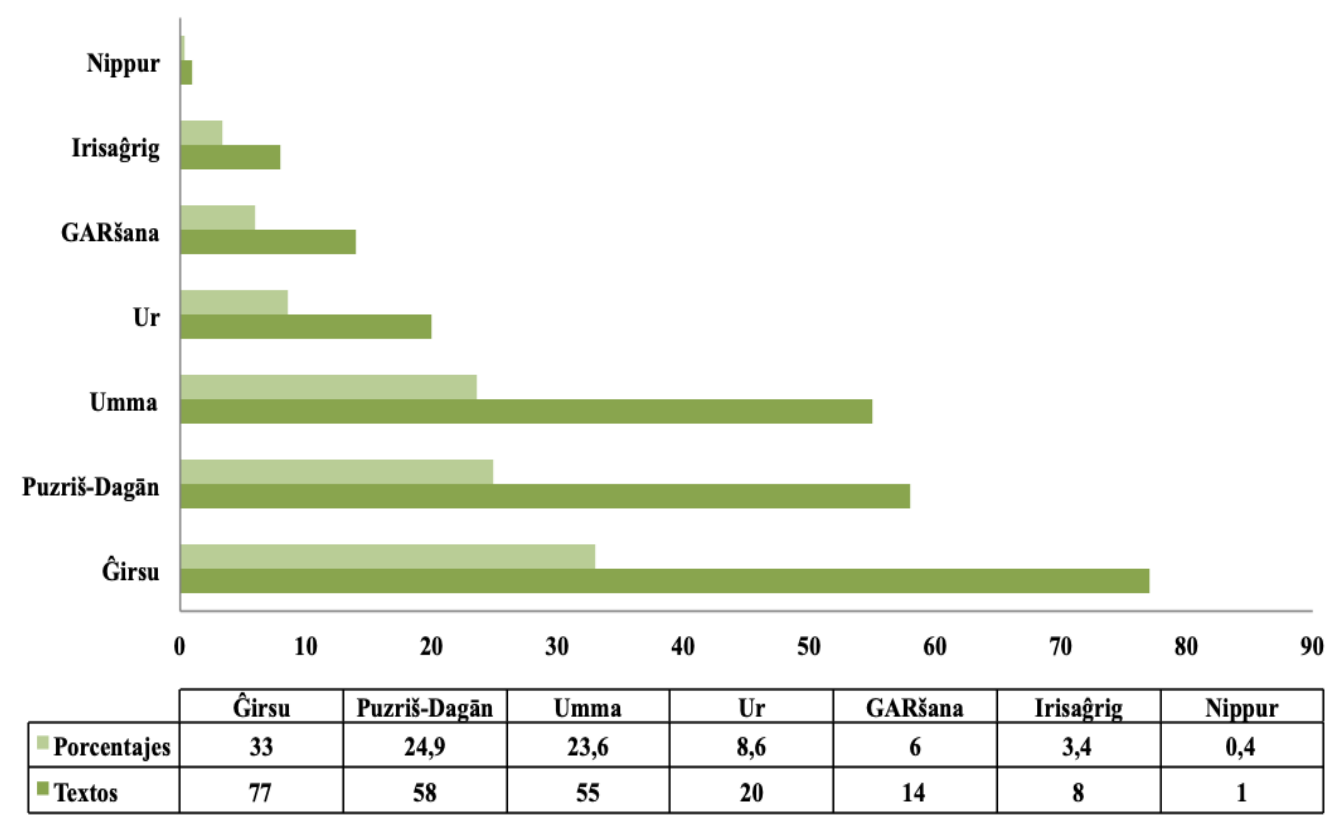

Tabla 2. Mención del ki-a-naĝ en los archivos de Ur III.

Table 2. Mention of ki-a-nâg in the archives of Ur III. 
reconoce una serie de cuestiones centrales para el estudio del contenido de las tablillas administrativas y sus contextos de producción/circulación durante Ur III, sobre todo en lo referente al funcionamiento de cuatro sitios en tanto "archivos" estatales: Ĝirsu (Tellō), Puzriš-Dagān (Tell Drēhim), Umma (Tell Ğoha) y Ur (Tell el-Muqejjir) (Molina 2008: 52 ss.). Se destacan también otras ciudades como localizaciones importantes, aunque para el caso del ki-a-naĝ, su ponderación no resulta significativa.

El centro neurálgico de la monarquía neo-sumeria fue la ciudad Ur, sede de la autoridad política y cabeza de una veintena de provincias, cada una en manos de un ensi ${ }_{2}$ ("gobernador"), cuyo poder nominal emanaba de un nombramiento real pero que, en la práctica, resultó hereditario (Steinkeller 2013: 351-352). En paralelo, estaban los šagina ("generales") designados por la corona, quienes residían en las capitales provinciales con cierta independencia y debían total obediencia al rey y al sukkal-mah ("ministro principal"). Cada ensi, se encargaba de la administración de las tierras de los templos y los šagina de las propiedades de la corona y de los colonos instalados en las provincias (Steinkeller 2013: 351-352).

La ciudad de Ĝirsu, capital de la provincia más próspera y grande de época neo-sumeria, fue excavada inicialmente por Ernest de Sarzec como parte de la misión francesa a fines del siglo XIX y contiene tablillas del PD como de Ur III en su mayoría descontextualizadas (Sharlah 2004: 3; Molina 2016: 22). Un total de 26619 (27,9\%) textos de Ur III proviene del sitio, de los cuales sólo 77 refieren al ki-a-naĝ. De época presargónica, especialmente del $e_{2}$ $\mathrm{mi}_{2}$ (o "casa de las mujeres") en Ĝirsu, donde residiría la esposa real (Bartash 2014), procede la documentación alusiva al ki-a-naĝ.

El sitio de Puzriš-Dagān, asentamiento fundado por Šulgi para la recepción y la posterior distribución de animales a los distintos confines del Estado, proporciona un total de $15647(16,2 \%)$ textos de Ur III repartidos entre el "Archivo del Calzado", el cual contempla la circulación no sólo de ganado sino también de bienes confeccionados a partir de animales, y el "Archivo del Tesoro", el cual refiere al desembolso de objetos realizados en diversos metales preciosos para miembros de la corte (Sharlah 2004: 4; Molina 2016: 23). De la totalidad de textos contabilizados hasta la actualidad, 58 refieren al ki-a-naĝ.

Finalmente, Umma alberga un archivo provincial compuesto por 29940 (30,2 \%) tablillas que podría ser considerado como la "Oficina fiscal" del gobernador (Sharlah 2004: 3), convirtiéndose en la ciudad de la que procede el mayor número de textos, de cuyo total contamos con 55 en referencia al ki-a-nag. Tanto PuzrišDagān como Umma comenzaron a ser saqueadas a partir de la década del diez del siglo XX, agudizándose la situación con los conflictos bélicos entre 1991 y 2003 (Molina 2016: 23). Por consiguiente, los tres archivos más importantes del Estado de Ur III se encuentran separados de sus respectivos contextos arqueológicos, sobre todo los dos últimos.

En el entramado burocrático mencionado, la elaboración de textos administrativos y la importancia de funcionarios encargados de su ejecución y archivado, le otorgó al palacio un rol fuerte, pero insuficiente si se consideran las alianzas tendidas con los poderes locales. El sistema de tributación y recaudación, sustentando en el engranaje señalado supra, fue organizado a partir del reinado de Šulgi, cuando se reconfiguraron las redes de vínculos políticos previos $y$, con ello, el corpus de arhivos cuneiformes fue fundamental para la conexión entre la corona y los poderes locales.

Por ello, el ki-a-naĝ durante Ur III operó no sólo a partir del acaparimiento de bienes por parte del palacio, sino que también cooperó en el diseño de un paisaje funerario, producto sobre todo de la praxis burocrática reflejada en los archivos cuneiformes.

En definitiva, el estudio del ki-a-naĝ en tanto espacialidad mortuoria a partir de una aproximación doblemente filológica y arqueológica, nos permitirá entender cómo lo material se puede analizar no sólo a partir de los artefactos y las estructuras, sino también por medio de la materialidad que supone la escritura, y comprender así el sentido de la dimensión funeraria en el contexto de los textos administrativos de Ur III.

La perspectiva teórica que se considera para el estudio de las tablillas administrativas de Ur III ha sido planteada por José M. Vaquer (2012) en un artículo referido a los aportes de la Semiótica y su aplicación a los estudios de la materialidad en Arqueología. En el presente trabajo, se procede a la aplicación de la propuesta de Vaquer teniendo en cuenta el siguiente itinerario teórico/metodológico: a) la dialéctica sujeto/objeto en el contexto epistemológico de las Ciencias Sociales; b) la escritura y la arcilla en la dicotomía sujeto/objeto; c) las tablillas de arcilla desde un enfoque peirciano; y d) las tablillas y la (re-)construcción de espacialidades y prácticas.

\section{Más allá de la escritura, más acá de la materialidad (i): la dialéctica sujeto/objeto en el contexto epistemológico de las Ciencias Sociales}

La modernidad otorgó un sitio privilegiado al texto y, en paralelo, colocó a la razón en un lugar sagrado frente a la oralidad e, incluso, lo emocional. En efecto, desde una mirada doblemente cientificista/racionalista, todo saber basado en la escritura o, mejor dicho, "documentado" fue colocado en primer término en detrimento de otros que habrían carecido del mismo. 
En segundo lugar, el saber basado en la escritura ocupó un sitio preeminente frente al que se fundaba en la oralidad, pero, en simultáneo, este último descansaba sobre un privilegio, que lo colocaba en un orden destacado a la vez, ya que era un conocimiento sustentado en el estudio de los sujetos a diferencia de un conocimiento que se cimentara en/desde los objetos.

De alguna manera, esto se tradujo en una tripartición gnoseológica que, dentro de las Ciencias Sociales, quedaría planteada en: a) la Historia como la disciplina de la escritura; b) la Antropología como la ciencia asociada a la oralidad; y c), finalmente, la Arqueología como una disciplina vinculada a los objetos. Esta división tripartita, la cual coloca a la Arqueología en un sitio subsidiario de las anteriores, ha sido fuertemente criticada, no sólo por basarse en concepciones decimonónicas, sino también por desconocer los entramados interdisciplinarios a partir de los cuales las demás Ciencias Sociales se valieron de los postulados arqueológicos y viceversa.

Una ciencia en diálogo con la cultura material pone de relieve otros procesos que no son reconocibles ni a partir de los textos, ni tampoco a partir de informantes, tal como sostiene Alfredo González Ruibal (2012):

"Una retórica arqueológica no necesita importar sus medios de expresión ni del discurso etnográfico ni de la expresión artística, aunque se deje influenciar por ambos. No rechaza tampoco la palabra como forma de manifestar el pasado: la escritura puede expresar la materialidad tan bien como las imágenes. La retórica de la arqueología tiene que estar basada en la materialidad y lo fragmentario y en una temporalidad compleja en la que se mezcle el pasado y el presente (...) En el inconsciente, en lo que se oculta o se niega, podemos encontrar muchas claves para entender una sociedad, de la misma manera que en lo que se reprime el psicoanálisis encuentra la clave de la personalidad de los seres humanos (...)" (González Ruibal 2012: 110-111).

Esta discusión de los humanos versus las cosas es producto, en parte, de la modernidad, tal como señala Bruno Latour (1991), donde los sujetos y los objetos fueron situados en compartimientos separados sin conexión. El abismo entre ambas entidades quedó establecido en parte por la dialéctica hegeliana y, por consiguiente, Latour defiende un conocimiento nomoderno en su crítica de las concepciones cientificistas modernas y posmodernas. Además, las Ciencias Sociales han ponderado las relaciones societales en detrimento de los vínculos que se plantean a partir de los objetos, los cuales se transformaron en meras representaciones de relaciones sociales, poniéndose de manifiesto así la dicotomía cultura/naturaleza.

Una de las cuestiones que se desprenden de la crítica de Latour (2005) apunta a reconsiderar los preceptos sobre los cuales se asienta la Teoría Social, proponiendo una "Teoría del Actor Red", en un intento por comprender cómo se conforma y fundamenta lo social. En su tesis, toda construcción social no se presentaría como algo preestablecido, sino que se sostiene en el dinamismo que posibilita la participación de los agentes humanos y no humanos (objetos, ideas, discursos, etc.). Pero, tal como observa Daniel Miller, mientras Latour está obsesionado en la búsqueda de la agencia no humana por debajo de la agencia humana, Alfred Gell está centrado en el estudio de los objetos a fin de analizar la agencia humana que estaría incrustada/contenida en los mismos (Miller 2005: 13).

Por otra parte, el concepto de "materialidad" supone para la Arqueología un debate mayor sobre la noción de objeto, ya que plantea la inclusión dentro del universo ontológico del artefacto, por ejemplo, a "lo efímero, lo imaginario, lo biológico y lo teórico" (Miller 2005: 4). En la postura de Daniel Miller, se conjuga la doble premisa heideggeriana del "ser-a-la-mano" (práctica) y el "serante-los-ojos" (teórica), y, por lo tanto, lo material si bien puede darse ante los ojos, permanece oculto o no lo vemos (2005: 5). De la misma manera, Alfredo González Ruibal afirma que lo material plantea la manifestación del inconsciente (2012: 111). En suma, siguiendo a Daniel Miller, la materialidad

"implica que mucho de lo que somos existe no por medio de nuestra consciencia o cuerpo, sino como un ambiente exterior que nos habita y estimula. Esta capacidad algo inesperada de los objetos para desvanecerse y permanecer periféricos a nuestra visión y todavía ser determinantes de nuestra conducta e identidad tendría otro resultado importante" (2005: 5).

Sin embargo, desde la Teoría de la Práctica, la cual retoma consideraciones específicas de la perspectiva fenomenológica y de la concepción materialista marxista, las cosas ocupan un lugar social que habla de las relaciones sociales y de un tipo de habitus (Bourdieu 1977). Por lo tanto, las cosas señalan un orden y establecen una codificación semejante a los roles de género y/o clase, es decir, son referentes del poder implícito de la reproducción social.

En cuanto a la perspectiva de la "objetivación", la misma permite entender en simultáneo "lo que las cosas son" y "lo que las cosas hacen en el mundo social" (Tilley 2006: 60). Explica la manera a través de la cual los "objetos" o "formas materiales están embebidas en el universo de vida de individuos, grupos, instituciones o, más ampliamente, sobre la cultura o la sociedad" (Tilley 2006: 60). Además, el proceso de objetivación -que ya había sido estudiado por Pierre Bourdieu- contribuye a la superación de la dialéctica sujeto/objeto, poniendo el énfasis en la imbricación existente entre las cosas y el universo de las relaciones humanas (Tilley 2006: 61). 
Una de las cuestiones centrales del mundo de los artefactos en sus ciclos de vida es la posibilidad de transformar sus significados a partir de sus usos y reapropiaciones (Tilley 2006: 71). De acuerdo a Christopher Tilley,

"los artefactos podrían de esta manera objetivar un evento particular de una transacción o aspectos de la identidad del agente de la transacción. Podrían objetivar también sitios particulares donde fueron realizados o intercambiados o lugares de los cuales las materias primas fueron obtenidas" (2006: 70).

Más allá de la escritura, más acá de la materialidad (ii): la escritura y la arcilla en la dicotomía sujeto/ objeto

Las tablillas de arcilla implican un tipo de materialidad, que los asiriólogos solamente habían estudiado desde una mirada filológica, sin tener en cuenta una perspectiva que ponga en discusión la consideración material misma del objeto portador de escritura. De forma paulatina, la materialidad como tópico analítico se ha incorporado afortunadamente a la discusión en Asiriología, que presentamos a continuación.

Un buen ejemplo es el libro editado por Thomas Balke y Christina Tsouparopoulou (2016), el cual tiene por objetivo abrir el juego a otras dimensiones que lo estrictamente filológico a la hora de abordar la documentación cuneiforme. De acuerdo a los autores, el estudio de las fuentes en el Próximo Oriente antiguo debería enfatizar "la materialidad de la escritura (como un acto) y la materialidad del texto (como un artefacto)" (Balke \& Tsouparopoulou 2016: 1). Además, el fetichismo de la escritura implicaba un proceso que ubicaba al aspecto textual en una dimensión superlativa sobre el objeto portador, del cual se separaba, para fundamentarse a partir de una dimensión sagrada (Tsouparopoulou 2016: 260-261).

En cuanto a la circulación de la palabra en Mesopotamia, puede pensarse a las tablillas administrativas de Ur III como objetos portadores de escritura y, por consiguiente, de "mensajes", pero también deberíamos reconocer a otras prácticas como mecanismos asociados a la transmisión y recepción del mensaje escrito, por ejemplo, los heraldos (niĝir) que realizaban declamaciones en voz alta frente a un auditorio y leían las cartas recibidas en la corte (Tsouparopoulou 2015: 16).

En este sentido, las sociedades del Próximo Oriente antiguo podrían ser entendidas más que como sociedades completamente letradas más bien atadas en un alto grado a la oralidad o, mejor dicho, como lo planteado Niek Veldhuis (2011), existieron distintos niveles de alfabetización, entre los que se destacan la "funcional", la "técnica" y la "erudita". Por consiguiente, la virtualidad que suponía el mensaje escrito necesitaba de otros canales para su difusión, aunque se reconocían distintos grados de apropiación de la escritura en cuanto técnica.

Sin embargo, la sobreestimación moderna de la escritura y su no desacralización conducen a la poca importancia que han tenido los objetos que conservaron los mensajes escritos. En efecto, podríamos considerar a los artefactos con inscripciones como objetos sociales vivos, ya que

"el portador del texto no es una entidad monolítica sino un agente social, marcado con improntas no textuales que introducen nociones de valor y significado, las cuales surgen de su materialidad" (Tsouparopoulou 2016: 257)

En relación al punto anterior, Kathyrin Piquette y Ruth D. Whitehouse (2013) ponen en cuestión otros tópicos referidos a la materialidad de los objetos que serían portadores de escritura, pero que, tradicionalmente, no fueron estudiados o habrían sido relegados a un último lugar para ser analizados. Siguiendo la línea trazada por las autoras, la consideración sobre la materialidad de la escritura supondría una superación no sólo epistemológica, sino que también apuntaría a reforzar el diálogo interdisciplinario para entender las sociedades del pasado, integrando a la Arqueología con la Filología (Piquette \& Whitehouse 2013: 2). Por ello, la escritura podría ser analizada como un "artefacto", $y$, por consiguiente, pensarse como un "componente dinámico del mundo social" que, además, se presentaría como "la teorización de lo 'material' en la cultura escrita" (Piquette \& Whitehouse 2013: 2).

Otra de las discusiones recuperadas por las autoras para pensar la escritura como un artefacto es la famosa tríada que James Gibson (1979) sintetizó en "substancia", "superficie" y "medio", es decir, los tres componentes que constituyen todo hábitat humano. Dicha tríada también fue retomada por Tim Ingold (2007) en su crítica a los estudios que se focalizan en la "materialidad", planteando una vuelta al estudio sobre los "materiales" y sosteniendo que siempre se habían ponderado los procesos de consumo más que los de producción y, por consiguiente, el punto de partida había sido el universo de los objetos. En palabras del autor:

"Puedo tocar la roca, ya sea de una pared de la cueva o del suelo bajo los pies, y así puedo tener una idea de cómo es la roca como material. Pero no puedo tocar la materialidad de la roca. La superficie de la materialidad, en definitiva, es una ilusión. No podemos tocarla porque no está allí. Como todas las demás criaturas, los seres humanos no existen en el "otro lado" de la materialidad, sino que nadan en un océano de materiales" (Ingold 2007: 7).

No obstante, el rechazo de Ingold de la noción de 
materialidad y su aplicabilidad es un tanto sesgada, ya que la misma permite considerar otros tópicos que antes no habían sido ponderados, por ejemplo, la materialidad del proceso de escritura. En este sentido, no sólo se hace foco en la escritura en tanto portadora de un mensaje sino también de una tecnología y, por tanto, como parte de una comunidad de hablantes y como praxis performativa de la realidad. Además, el concepto de materialidad, tal como señalábamos al comienzo de este apartado, implica una superación de la mirada monolítica centrada en la escritura y, de este modo, poder considerar así los soportes empleados y los actores involucrados en el proceso. De acuerdo con Piquette y Whitehouse, el concepto de materialidad

"(...) puede ser útil para distinguir entre una noción necesariamente pasiva de "material" (sustancia) que precede al análisis y la interpretación, y un concepto más activo que involucra el material que se incorpora posteriormente a una narrativa de prácticas marcadas socialmente situadas. La "materialidad" puede, por lo tanto, referirse de manera general a los aspectos materiales de los artefactos, mientras que también, y lo que es más importante, suscita su situación en relación con conjuntos de prácticas que se informan mutuamente. Esto permite que el material se describa como algo más que un simple "soporte" para escribir. Se activa en la construcción de significados, desde el trabajo preliminar de fabricación de artefactos en blanco sobre el cual se hacen las marcas y las técnicas de transformación de superficie que dan lugar a las marcas escritas, hasta las formas en que estos objetos físicos se incorporaron a las siguientes" (2013: 3)

\section{Más allá de la escritura, más acá de la materialidad (iii): las tablillas de arcilla desde un enfoque peirciano}

El análisis realizado por Ferdinand de Saussure (1995 [1916]) sobre el signo lingüístico considera, desde una perspectiva dicotómica, una diferenciación tajante entre concepto/significado e imagen acústica/significante. La asociación significado/significante sería arbitraria y se articularía en el cerebro humano. La mirada semiológica saussureana plantea una separación radical de los signos del universo material. Por ello, en nuestro análisis, proponemos una revisión de este posicionamiento dialécticoy, tal como sostiene Webb Keane, consideramos oportuno "desarrollar una aproximación a los signos por los cuales el carácter práctico y contingente de las cosas no está subordinado ni aislado de la comunicación y el pensamiento" (2005: 183). La superación de la mirada estructuralista saussureana permite entender que "la cultura material posee características distintivas que operan en niveles de significación diferentes que la lengua" (Vaquer 2014: 58).

La línea de trabajo de Keane se nutre de la perspectiva peirciana, la cual se sintetiza en la propuesta teórica del "sinequismo" (Preucel 2006: 49). Charles Peirce emplea dicho concepto para analizar cuestiones referidas a la ontología del ser y también para entender el devenir.

En relación al análisis del signo lingüístico, la perspectiva peirciana lo entiende en clave triádica y, por ello, rompe con la visión estructuralista dialéctica saussureana al incorporar una tercera dimensión: el interpretante (Preucel 2006: 54). En efecto, desde este enfoque, el signo existiría en un proceso de semiosis conectado con el pasado y proyectado hacia el futuro. Además, todo signo no podría acontecer de manera aislada, sino que formaría parte de un conjunto infinito que estaría en transformación constante y, por lo tanto, apuntaría hacia atrás en el pasado a un objeto y hacia adelante en el futuro a un interpretante (Preucel 2006: 55). Por otra parte, todo signo posee vida propia y, por ello, tiene la capacidad de generar otros signos en un proceso infinito de semiosis, es decir, es portador de "agencia" (Preucel 2006: 55-56). En este sentido, la perspectiva pragmatista de Peirce señala que toda relación de significación se constituye, desarrolla y continúa a través de la práctica y, además, es un proceso infinito y que no
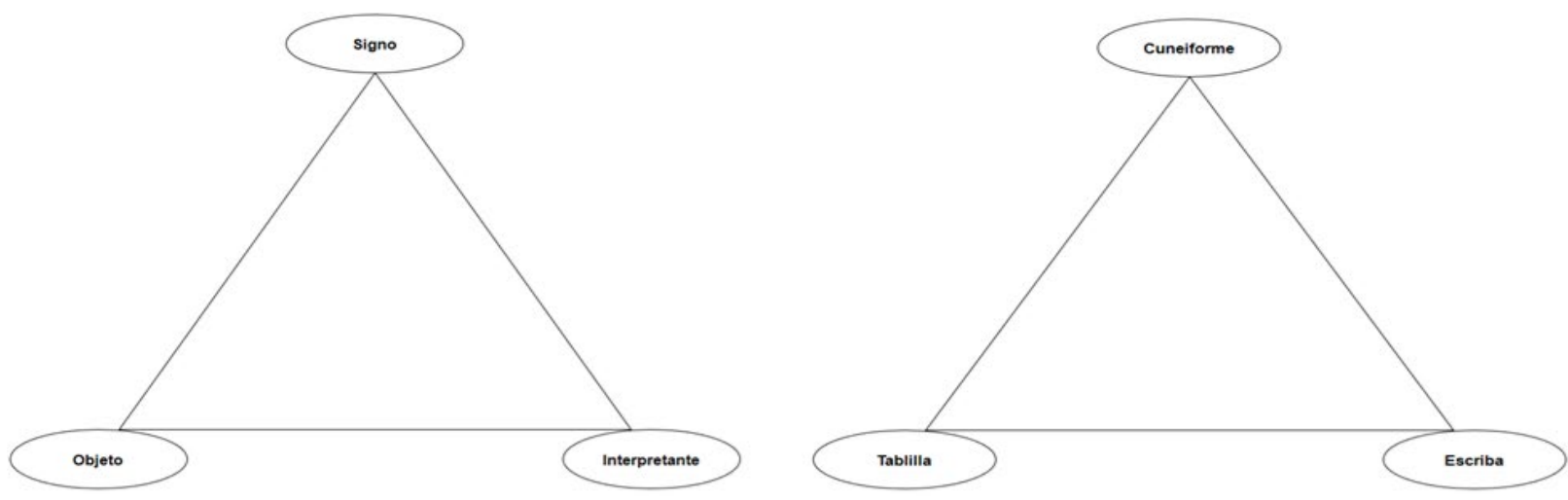

Figura 1. Modelo pierciano de signo lingüístico. a) Modelo semiótico pierciano. b) Aplicación del modelo pierciano para analizar la evidencia mesopotámica.

Figure 1. Piercian model of linguistic sign. a) Piercian semiotic model. b) Application of the Piercian model to analyze mesopotamian evidence 
se extingue, ya que todo signo puede a su vez aparecer como signo de otra cosa (Vaquer 2014: 58).

En nuestro caso, la tríada signo/objeto/interpretante la hemos sintetizado en la tríada (escritura) cuneiforme/ tablilla (de arcilla)/escriba (Figura 1). Sin ánimos de reducir el modelo peirciano de signo lingüístico a las categorías que hemos señalado, dicha concepción triádica serviría para explicar la materialidad que supondría la práctica de la escritura en la Mesopotamia antigua.

La consideración triádica del signo lingüístico posibilita que contemplemos la ligazón existente entre la escritura (y aquí tendríamos los aspectos epigráficos y paleográficos desde una doble ponderación sincrónica y diacrónica en cuanto al desarrollo de los signos cuneiformes), su soporte (en este punto, sería fundamental la importancia que poseía el uso de determinado material para plasmar, conservar, reproducir y hacer circular el mensaje escrito, e.g. la arcilla húmeda o la piedra) y el escriba/ interpretante (el cual, en tanto agente participaría de la materialidad de la tablilla/objeto desde el momento de su confección, almacenaje y/o transporte).

En este sentido, creemos que el enfoque propuesto por José M. Vaquer (2012), basado en tres herramientas teórico/metodológicas, algunas de las cuales ya hemos señalado, permite un análisis macro e integrador de las cuestiones que indicamos hasta aquí. Dicho autor plantea tres niveles interpretativos, los cuales se basan en las siguientes premisas: a) la Teoría Social (en este caso, se hace referencia a la Teoría de la Práctica, e.g. Pierre Bourdieu o Anthony Giddens); b) la Semiótica de Charles Peirce en conexión a los estudios de la materialidad; y c) la Arqueología Conductual, la cual integra el concepto de perfomance que refiere a la posibilidad de un objeto para actuar en el contexto de las relaciones sociales (Vaquer 2012: 162-163).

Asimismo, la tríada signo/objeto/interpretante podría dar lugar a una tipología de signos que hemos resumido en la Tabla 3 y que refiere a: la relación del signo consigo mismo, el vínculo del signo con el objeto y, finalmente, el nexo entre el signo y el interpretante (Preucel 2006: 56). En esta concepción triádica del signo, la relación signo/signo (representamen) refiere al punto inicial

Tabla 3. La relación triádica de los signos (adaptado de Preucel 2006: 56).

Table 3. The triadic relation of the signs (adapted from Preucel 2006: 56).

\begin{tabular}{cccc}
\hline Signo & Primeridad & Secundidad & Terceridad \\
\hline Signo/signo & Cualisigno & Sinsigno & Legisigno \\
Signo/objeto & Ícono & Índice & Símbolo \\
Signo/interpretante & Rema & Decisigno & Argumento
\end{tabular}

de la semiosis o primeridad; la de signo/objeto a la secundidad; y la de signo/interpretante a la terceridad.

De acuerdo a la clasificación propuesta por Peirce para entender las relaciones triádicas del signo, podemos reflexionar sobre la explicación que hemos articulado en la Tabla 4, aplicándolo al análisis de las tablillas cuneiformes.

En la relación de signo/signo, podemos distinguir, primero, al cualisigno, que refiere a una cualidad del signo. En nuestro caso, hemos tomado el signo empleado para realizar el número 10 (cuyo sonido era $u$ ) y que se escribía con la parte de la cabeza del cálamo y, de ahí, su nombre actual Winkelhaken o "gancho angular". Lo curioso es que el signo aislado no representaba nada, sino que necesitaba ponerse en relación a otro conjunto de signos, por ejemplo, la palabra "día" o para expresar una cantidad en particular. Este criterio se podría aplicar a propósito de las cuñas que se combinaban para formar los distintos signos cuneiformes, las cuales, a pesar de su significado per se necesitaban estar combinadas. Es decir, la escritura cuneiforme se valió de cinco cuñas con los siguientes significados: - , aš, "uno", pero que también admitía la lectura $\mathrm{ge}_{15}$, es decir, "trazo del estilo" o "cuña"; I , diš, que también se usaba para representar a la unidad y podía adoptar el sonido ge $_{3^{\prime}}$ con el mismo significado que en el caso anterior; $\backslash$, dištenû o ge 23' $^{\prime}$ "trazo"; \, ge ${ }_{22^{\prime}}$ ídem anterior; y < , u ("diez", "totalidad", "agujero", etc.), bur ("unidad de medida para superficies"), giguru ("borde"), ge ${ }_{14}$ ("trazo"), etc. Por ejemplo, el signo gal ("grande") resulta de la combinación de cinco aš y un diš. Volviendo a la consideración del cualisigno o relación signo/signo como primeridad, se puede pensar en el valor polisémico del signo < y la necesidad de un contexto para definir su significado específico o 囬, el cual, es propiamente una cualidad que podría dar lugar, por ejemplo, a "hombre grande" (lu 2 -gal = lugal), i.e. "rey".

La relación de signo/signo en su secundidad es el sinsigno, es decir, la cualidad de un signo encarnada en un objeto, como podría ser el uso de ㄱ para formar , es decir, e-gal, "casa grande" y, por ende, la casa del lugal ("rey"), el "palacio".

Posteriormente, el nexo signo/signo en el orden de la terceridad se denomina legisigno, el cual indicaría cómo el signo representa una ley o un hábito y, por lo tanto, resulta de una convención. Por ejemplo, todo nombre de una divinidad se escribía antecedido por el signo * (diĝir), que significa "dios", pero, en este caso, operaba como un determinativo divino, el cual no era leído, sino que funcionaba como una marca escrita de un teónimo.

Otra cuestión importante en el análisis peirciano apunta a la relación signo/objeto o de ejecución, la cual se 
Tabla 4. Relación triádica de los signos en la escritura cuneiforme.

Table 4. Triadic relation of the signs in the cuneiform writing.

\begin{tabular}{|c|c|c|c|}
\hline & Primeridad & Secundidad & Terceridad \\
\hline \multirow{3}{*}{ Signo/signo } & Cualisigno: & Sinsigno: & Legisigno: \\
\hline & $\varangle(u)=10$ & IIn $\left(e_{2}-g a l\right)=$ & $($ digir $)=$ dios $/$ \\
\hline & $\begin{array}{l}\text { grande } \\
\text { gal }=\end{array}$ & palacio & determinativo divino \\
\hline \multirow[t]{3}{*}{ Signo/objeto } & Ícono: & Índice: & Símbolo: \\
\hline & 番来 $(\mathrm{mul})$ & 的 $\left./ 2 u_{7}\right)=$ & 的 \\
\hline & $=$ estrella & comer & de la sexualidad y la guerra) \\
\hline \multirow[t]{17}{*}{ Signo/interpretante } & Rema: & Decisigno: & Argumento: \\
\hline & $\infty / 4$ & 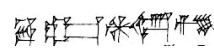 & \\
\hline & $=$ sol & $=$ & \\
\hline & & iti ezem & 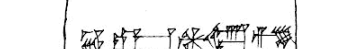 \\
\hline & & dŠulgi (lit. & 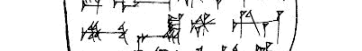 \\
\hline & & "mes del festival & 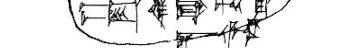 \\
\hline & & de Šulgi") & 7. iti ezem ďsulgi $=$ \\
\hline & & & "mes del festival de Šulgi" \\
\hline & & & (mes 8 del calendario de \\
\hline & & & Puzriš-Dagān) \\
\hline & & & 8. mu en ${ }^{d}$ Inanna \\
\hline & & & 9. $U n u^{k i}-g a \quad m a \check{S}_{2}-e$ \\
\hline & & & $\mathrm{i}_{3}-\mathrm{pa}=$ año en el que el \\
\hline & & & sacerdote-en de Inanna por \\
\hline & & & aruspicina (Ibbi-Su'en) fue \\
\hline & & & escogido en Uruk (año 2 del \\
\hline & & & reinado de Ibbi-Su'en) \\
\hline
\end{tabular}

imágenes de rosetas se utilizaban como símbolos de la fertilidad (Miller 2013: 128) y evocaban, por lo tanto, a Inanna, la diosa de la fecundidad por antonomasia, cuyo nombre también resultaba de la combinación de los signos * $*$ (AN.MUŠ $)$.

Para concluir el análisis de relaciones triádicas de Peirce, debemos considerar el vínculo signo/interpretante (Precuel 2006: 56-57). En principio, tenemos el concepto de rema, el cual refiere a un término en tanto unidad de sentido, por ejemplo, el vocablo "sol" ( $\left.u_{4} \cdot d\right)$, así como cualquiera del léxico sumerio. Particularmente, el pictograma para el rema sol $O$ se transforma en el cuneiforme $\Rightarrow y$, dada, la polifonía/ polisemia de los signos cuneiformes no sólo podía adoptar otros sonidos, sino también otros sentidos. En efecto, el vocablo "sol" también era utilizado para significar "día" o "luz" y, obviamente, era un indicador de tiempo en los calendarios. En orden de secundidad, en la relación signo/interpretante, encontramos el concepto de decisigno (o dicente), el cual coincide con la noción de "enunciado" y, por ende, posee signficado. A propósito, la frase iti ezem dŠulgi significa literalmente "mes del festival de Šulgi". No obstante, ese nombre de mes está asociado con un calendario específico de una ciudad y con un período también en particular. En efecto, se da un tercer nivel u orden

sintetiza también a partir de una perspectiva también triádica (Preucel 2006: 56). En primer lugar, podemos considerar al ícono en una relación de primeridad, la cual es mimética, como podría ser el nexo entre una persona y una fotografía. En nuestro caso, la escritura cuneiforme, a diferencia del jeroglífico egipcio, atravesó un proceso de abstracción que condujo a la simplificación de muchos de sus signos, aunque algunos conservaron el aspecto pictográfico de las etapas precedentes, como ocurre con 宷米 (mul), "estrella". En segundo término, tenemos al índice, el cual es un signo que denota su objeto dado que está modificado por el mismo, es decir, existe una ligazón estricta, por ejemplo, el verbo "comer" en sumerio $\left(\mathrm{gu}_{7}\right)$ se escribe en el sistema pictográfico con una cabeza humana con un cuenco cerámico a la derecha $\mathbb{P}$, que luego dio lugar a Los cuencos cerámicos en tumbas también tuvieron un carácter indiciario $\mathrm{y}$, por lo tanto, eran evocativos de la ofrenda funeraria. Finalmente, como relación de terceridad, aparece el símbolo, el cual es un signo que posee su carácter a partir de una ley o convención, que permite su asociación con un objeto. Por ejemplo, las de terceridad en la relación de signo/interpretante que se denomina argumento y que posee significación. En relación a este punto, es importante la idea de contexto, ya que la combinación de varios decisignos constituye un argumento que adopta una significación especial en un ámbito determinado. Por tal motivo, los nombres de meses y años en particular refieren a un campo de significación específico:
7. iti ezem ď̌ulgi
mes del festival de Šulgi (mes 8 del calendario de Puzriš- Dagān)
8. mu en dInanna año en el que sacerdote-en de Inanna
9. Unu $\mathrm{ki}_{\mathrm{i}}$-ga maš 2 -e i $\mathrm{i}_{3}$-pa (Ibbi-Su'en) escogió por aruspicina (año 2 del reinado de Ibbi-Su'en)

De este modo, la información suministrada en el reverso de la tablilla AUAM 73.0788 (líneas 7-9) permite establecer una cronología del texto: en este caso, el 
mes 8 del calendario de la ciudad de Puzriš-Dagān del segundo año del reinado de Ibbi-Su'en.

La consideración triádica del signo es importante ya que incluye un tercer elemento, el interpretante, que nosotros hemos denominado escriba $y$, de acuerdo al ejemplo de la tablilla AUAM 73.0788, se servía de determinados enunciados para construir un universo de significación específico, i.e. empleaba un argumento coherente con la ideología del período. En este caso, debía ser preciso en el conocimiento del calendario de la época.

Entonces, a partir de lo anterior, cabría preguntarnos por las tablillas de arcilla, las cuales se transformaron en el soporte para la escritura cuneiforme, donde se registraban, por cierto, los diferentes aspectos de la vida cotidiana de los mesopotámicos. A propósito, si tenemos en cuenta como punto de partida a la arcilla y no a la tablilla en cuanto objeto/artefacto, podemos determinar qué tipo de texto iba a imprimirse sobre la misma (Cabrera 2017: 6).

En las escuelas de escribas, las mejores arcillas se empleaban para la elaboración de textos de mayor complejidad, como la literatura, y las de una calidad inferior se utilizaban en la producción de textos administrativos, donde se registraban, por ejemplo, los bienes que circulaban en calidad de ofrendas funerarias hacia los sitios construidos en honor de los difuntos. Asimismo, dadas las diferencias que existían entre ambos tipos de arcilla, unas permitían la realización de textos de dimensiones más grandes mientras que las otras no.

Las tablillas que contenían los textos lexicales eran de una hechura mejor que las administrativas e, incluso, se asemejaban a las literarias. A partir de ello, se podría elaborar una especie de taxonomía al considerar el material con el que la tablilla se producía, y, además, inferir qué circulación admitía al interior de la sociedad. En este caso, las tablillas lexicales poseían un fin pedagógico de la misma manera que las literarias, dado que las copias encontradas provienen de escuelas de escribas y, seguramente, eran utilizadas para aprender no sólo el uso de la escritura sino también las lenguas del momento.

Por último, en tanto praxis social, la escritura en Mesopotamia, sobre todo durante Ur III, puede pensarse como una herramienta asociada al sostenimiento del estado y su respectiva legitimación, ya que los escribas, en calidad de agentes estatales, fueron necesarios en la reproducción ad infinitum de la ideología del centro. De este modo, las tablillas contenedoras de textos administrativos, desde su misma composición material en un tipo específico de arcilla, así como también a través de su materialidad y carácter indiciario dan cuenta de un habitus $y$, por consiguiente, sirvieron como medio de difusión y definición del paisaje funerario, cuyo objetivo fue la vindicación de las elites asociadas al palacio. Este proceso de legitimación política y centralización estatal no hubiera sido posible sin la propagación de textos administrativos realizados en tablillas de arcilla de hechura estandariza y rápida parte de los escribas en tanto miembros de la burocracia estatal.

\section{Más allá de la escritura, más acá de la materialidad (iv): las tablillas y la (re-)construcción de espacialidades y prácticas}

La (re-)construcción y definición de espacialidades en Mesopotamia puede ser abordada a partir del estudio y análisis de la epigrafía en diálogo permanente con la evidencia material. Nuestra propuesta hace foco en la dimensión funeraria desde su misma materialidad $y$, en relación a este último punto, entendemos no sólo el registro arqueológico de los enterramientos en sí mismos sino también la documentación epigráfica, la cual arroja información de elevada importancia sobre los paisajes funerarios. A propósito del enfoque semiótico que comentábamos en el punto precedente, cobra trascendencia el concepto de argumento en relación a la dualidad signo/interpretante, puesto que aporta información sobre el contexto de significación. Por tal motivo, entendemos que "construir" un espacio, en el marco de las sociedades del Próximo Oriente antiguo, estaba en absoluta armonía con la idea de "habitar". Sin embargo, como sostiene John Barrett, la condición para habitar no sólo implica la capacidad de ocupar un lugar, sino también un "proceso de entender la relevancia de las acciones ejecutadas en el mismo lugar por referencia a otras épocas y a otros lugares" (1999: 260).

En efecto, "habitar" y "construir" son íntegramente congruentes con los modos de existir de cada sociedad. De alguna manera, el primero parece pre-existente a la premisa de "construir", objetivo último del anterior. A propósito, en 1951, Martin Heidegger reflexiona en una conferencia titulada "Construir, habitar, pensar", acerca de la dialéctica humano/espacio y afirma que "construir" no sólo alude existencialmente a la idea de "habitar" sino que, de forma primigenia, se relaciona con el "ser". En palabras del autor:

"La palabra del alto alemán antiguo correspondiente a construir, buan, significa habitar. Esto quiere decir: permanecer, residir. El significado propio del verbo bauen (construir), es decir, habitar, lo hemos perdido (...) Allí donde la palabra construir habla todavía de un modo originario dice al mismo tiempo hasta dónde llega la esencia del habitar. Bauen, buan, bhu, beo es nuestra palabra «bin» («soy») en las formas ich bin, du bist (yo soy, tú eres), la forma de imperativo bis, sei, (sé). Entonces ¿qué significa ich bin (yo soy)? La antigua palabra bauen, con la cual tiene que ver bin contesta: «ich bin», «du bist» quiere decir: yo habito, tú habitas. El modo como tú eres, yo soy, la manera según la cual 
los hombres somos en la tierra es el Buan, el habitar. Ser hombre significa: estar en la tierra como mortal, significa: habitar. La antigua palabra bauen significa que el hombre es en la medida en que habita; la palabra bauen significa al mismo tiempo abrigar y cuidar; así, cultivar (construir) un campo de labor, cultivar (construir) una viña" (Heidegger 1994: 128-129).

La cita anterior plantea que el espacio no es una simple abstracción donde las actividades humanas acontecen ya que no es ajeno a las transformaciones epocales, de cuya variable tiempo, por lo tanto, no se separaría (Tilley 1994: 9). En ese sentido,

"[e]l ser-en-el-mundo reside en un proceso de objetivación en el cual la gente objetiva el mundo poniéndose aparte del mismo. Esto da lugar a la creación de una brecha, una distancia en el espacio. Ser humano es crear esta distancia entre el yo y lo que está más allá y tratar de salvar esta distancia a través de una variedad de medios: a través de la percepción (ver, oír, tocar), acciones y movimientos corporales, e intencionalidad, emoción y conciencia que reside en sistemas de creencias y toma de decisiones, recuerdo y evaluación" (Tilley 1994: 11-12).

A partir de la tríada existencial habitar/construir/ser, nos preguntamos por los modos de existir en la antigüedad, de qué manera era percibido el espacio en dicho contexto y, en suma, cómo se configuraban los paisajes funerarios apelando a la tríada espacio/tablilla/agente (Figura 2).

La Figura 2 arroja información sobre la manera en que las tablillas en tanto objetos están vinculadas a un tipo de signos referidos al espacio y activados por un escriba, el cual los actualiza constantemente con su uso en la documentación. Del mismo modo, la monumentalización de la espacialidad presupone el (re-)conocimiento de un mundo pre-existente, de un corpus de enunciados que se combinan en la construcción de un argumento. De esta manera, el paisaje funerario podría entenderse desde la perspectiva peirciana como un argumento en el que los agentes sociales contribuyen activamente en la construcción de su significación. En efecto, como sostiene John Barrett,

"[e]n lugar de ser parte del medio por el cual las prácticas sociales ganaron su vitalidad, los monumentos simplemente se tratan como un registro de esas prácticas. Al mismo tiempo, el ambiente "natural" más amplio parece haber operado como un conjunto de restricciones pasivas relativas sobre las cuales se promulgaron diversas prácticas sociales" (1999: 256-257).

En relación a la descripción de un espacio funerario, las fuentes -en este caso, nos referiremos solamente a las administrativo/económicas- plantean una diferenciación entre ki-mah, literalmente "lugar preminente" (kimahhu en acadio), y ki-a-naĝ ("lugar para beber agua"), el primero como "tumba" o "enterratorio" (a veces, como "cementerio") y, el segundo, como "capilla mortuoria" (Sallaberger 1993: 63-65, 70 y 94; Jagersma 2007: 294; Cabrera 2016). El término ki-mah escasamente sobrepasa la decena de registros para el PD IIIb y Ur III, mientras ki-a-naĝ se encuentra 47 veces durante el primer período y 324 en época neo-sumeria. El ki-a-naĝ no es mencionado en las inscripciones reales ni en las listas lexicales, solamente en tablillas administrativo/ económicas -como el vasto archivo del $\mathrm{e}_{2}-\mathrm{mi}_{2}$ de Lagaš$y$, por tanto, debe pensarse que no fueron construidos para los dioses sino para los muertos (Kobayashi 1985: 10 y 16). Además, la tablilla no sólo como depositaria de un mensaje escrito, sino como manifestación de una materialidad, permite dar cuenta en tanto objeto de las circunstancias sociopolíticas del momento: en este caso, la definición de un espacio conmemorativo de los muertos asociados a la elite $y$, además, la circulación y acaparamiento de bienes en carácter de ofrendas funerarias (Cabrera 2017).

Asimismo, el ki-a-nâg era el sitio previo a la sepultura del muerto, tal como se explicita en los textos (Jagersma 2007: 296-297). En él, se colocaría el cadáver para la celebración de un ritual vinculado con la depositación de ofrendas funerarias, además de figurar como el lugar en el que acontecía una ceremonia de lamentación.

En la tablilla VAT 7191, datada en el primer año de reinado de Ibbi-Su'en, se mencionan los antepasados reales, a los cuales se les rendía culto en el ki-a-naĝ y se les entregaba distintos tipos de ofrendas como las šuginû en un ritual nocturno conectado con la luna creciente y la luna llena (Sallaberger 1993: 64). En el texto completo (aquí sólo hemos recogido las líneas del anverso), aparecen los cuatro antecesores de lbbiSu'en. En la parte seleccionada, se alude al fundador de la dinastía, Ur-Namma, al suegro de este último, Apilkin, y Amar-Su'ena.
1. 360 sa gi
360 paquetes de cañas
2. $\mathrm{sa}_{2}-\mathrm{du}_{11}$ šu-a-ge-na (como) entregas šuginû.

Figura 2. Modelo peirciano para analizar los paisajes funerarios.

Figure 2. Peirciano model to analyze the funerary landscapes.

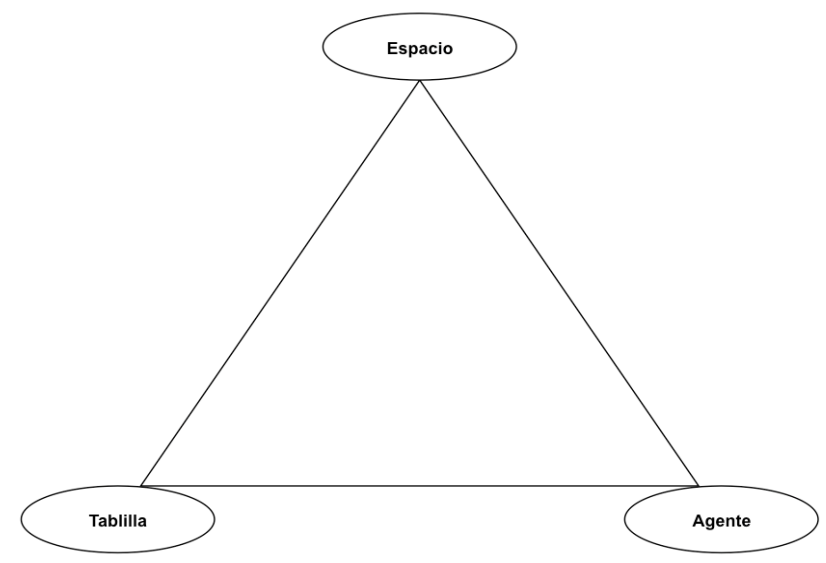



3. 20 sa gi
20 paquetes de cañas
4. $u_{4}$-sakar $u_{3} e_{2}-u_{4}-15$
(durante) la luna nueva y la luna llena
5. ki-a-naĝ Ur-dNamma (para) la capilla funeraria de Ur-Namma.
6. 120 sa gi sa ${ }_{2}-d_{11}$ A-pil 2 -ki-[in] 120 paquetes de cañas (como) entregas para Apilkin.
7. 150 sa 'gir 150 paquetes de [cañas'
8. $\mathrm{sa}_{2}-\mathrm{du}_{11}{ }^{\mathrm{d}}$ Amar-dSuen (como) entregas regulares para Amar-Su'ena
9. $\mathrm{s}_{3} \mathrm{e}_{2}$ Ur-d Namma en el templo de Ur-Namma. 10. 1200 sa gi sa $\mathrm{de}_{2}$ šu-a-ge-na 1200 paquetes de caña como entregas šuginû.

La capilla funeraria, en los archivos del PD Illb, se asociaba a determinados topónimos (ki-a-naĝ-Lagaški, ki-a-naĝ-NINA ${ }^{k i}$, etc.), títulos de gobernantes (ki-a-naĝlugal o ki-a-naĝ-ensi ${ }_{2}$ ) o nombres específicos. De este modo, se convirtió en el sitio privilegiado para el culto de los monarcas muertos -y tal vez sus parientes próximos, e.g. su esposa- y funcionó como un dispositivo monumentalizador del poder real (Cabrera \& Calomino 2016: 114-115). En caso de que el muerto fuera deificado, el ki-a-naĝ podría compararse con un templo (Kobayashi 1985: 25) y, por ende, constituía un espacio de disputa económico/política con la mencionada "gran organización" (Cabrera \& Calomino 2016: 120).

En la dialéctica templo/palacio, la problemática del kia-naĝ señala la configuración de un nuevo espacio destinado a la depositación de las ofrendas para los muertos, el cual entró en competencia por el control de la circulación de bienes con la gran organización del templo en tanto gran casa institucional, la cual comenzó a perder prerrogativas frente a otras esferas de poder.

En suma, el ki-a-nag fue la expresión material del poder secular personificado por la institución monárquica, la cual se sirvió de él como una nueva base de sustentación para competir con el templo, tal como se observa a partir de la llegada al poder de Iri-inim-gi-na durante el PD IIIb. Su advenimiento al trono implicó un cuestionamiento a las formas tradicionales de control político y el uso de estrategias, tanto discursivas como materiales, daban cuenta de esa transformación (Molina 1995: 60 ss.), en el que el ki-a-naĝ subrayó la importancia del paisaje funerario.

Por consiguiente, el estudio de la espacialidad funeraria no debe realizarse aisladamente sino en conjunción a las prácticas sociales sobre las que se establece. Así, la aparición de un sector del poder conectado a la esfera secular implicó disputar la hegemonía ejercida por el templo en cuanto gran organización. De manera tal, en paralelo a las disputas establecidas entre el templo y el palacio a partir del PD IIIb en cuanto "grandes casas" institucionales que estaban en pugna en la Baja Mesopotamia (Garfinkle 2013), podemos reconocer la importancia económica, política e ideológica del ki-anaĝ.

Durante el PD III, las tumbas reales de Ur se manifiestan como las estructuras de enterramiento más antiguas de la región que acusan la emergencia de un sector nuevo de la elite (Woolley 1934). No obstante, los enterratorios, en calidad de espacios evocativos de los muertos, también estuvieron vinculados con la vida social del sector dirigente del momento, tal como lo señalan los cuencos cerámicos depositados y los tubos para el drenaje que emergían hacia el exterior (Woolley 1934: 224), empleados para realizar libaciones (Cohen 2005: 28), como ocurría en el ki-a-naĝ. Podríamos pensar, por consiguiente, que los tubos eran utilizados para fines rituales. Según Nicola Laneri, en paralelo a la planificación de enterratorios de elite, las costumbres funerarias apuntaron a la materialización ideológica de los nacientes sectores dirigentes vinculados al palacio, quienes se habrían apropiado además de las prácticas discursivas asociadas a los templos (2008: 204).

Los tubos de terracota poseían un carácter indicial y, debido a ello, plantean una relación de secundidad del tipo signo/objeto, en la que dicho dispositivo arquitectónico funerario también se constituía en referente de las ceremonias conmemorativas en honor a los muertos (i.e. los antepasados reales). En su análisis del calendario cúltico de Mesopotamia, Mark Cohen (1993) sostiene que el vocablo a-bu-um ("montículo para uso funerario") tendría su origen en los cambios y la reorganización del estado durante Ur III. El vocablo a-bu-um también significa "festival" y se vinculaba con la realización de libaciones para los difuntos. En acadio, apu puede traducirse como "agujero" o "apertura en el suelo" (CAD A2: 201). De ser un objeto específico, en tanto estructura arquitectónica, se habría transformado en una ceremonia conectada con la dimensión mortuoria durante Ur III. Posteriormente, en el período paleobabilónico, abum/apum se empleó como nombre para uno de los meses del calendario (Cohen 1993: 259-261). La tablilla UET 2, 244, datada en el año 9 de Ibbi-Suen, refiere al a-bu-um en tanto ritual que se llevaba a cabo para evocar la memoria del fallecido rey Ur-Namma (Cohen 1993: 149):
1. $2 \mathrm{gu}_{4}$
2 bueyes:

2. nig $\hat{g}_{2}$-dab ${ }_{5}$ a-bu-um-ma provisiones para el festival a-bu-um

3. $1 \mathrm{gu}_{4} \quad 1$ buey:

4. ni $\hat{g}_{2}-\mathrm{dab}_{5}$ ezem dNin-a-zu provisión para el festival de Ninazu.

5. $1 \mathrm{gu}_{4} \quad 1$ buey:

6. nig $\hat{g}_{2}$-dab ${ }_{5}$ ezem diĝir-hul ${ }_{2}$ provisión para el festival de digîr-hul ${ }_{2}$.

r. 7. nig $\hat{g}_{2}-$ dab $_{5}$ ki-a-nag (Provisiones) para la capilla funeraria

8. Ur-dNamma-ka

9. zi-ga ki Du-du-ta 


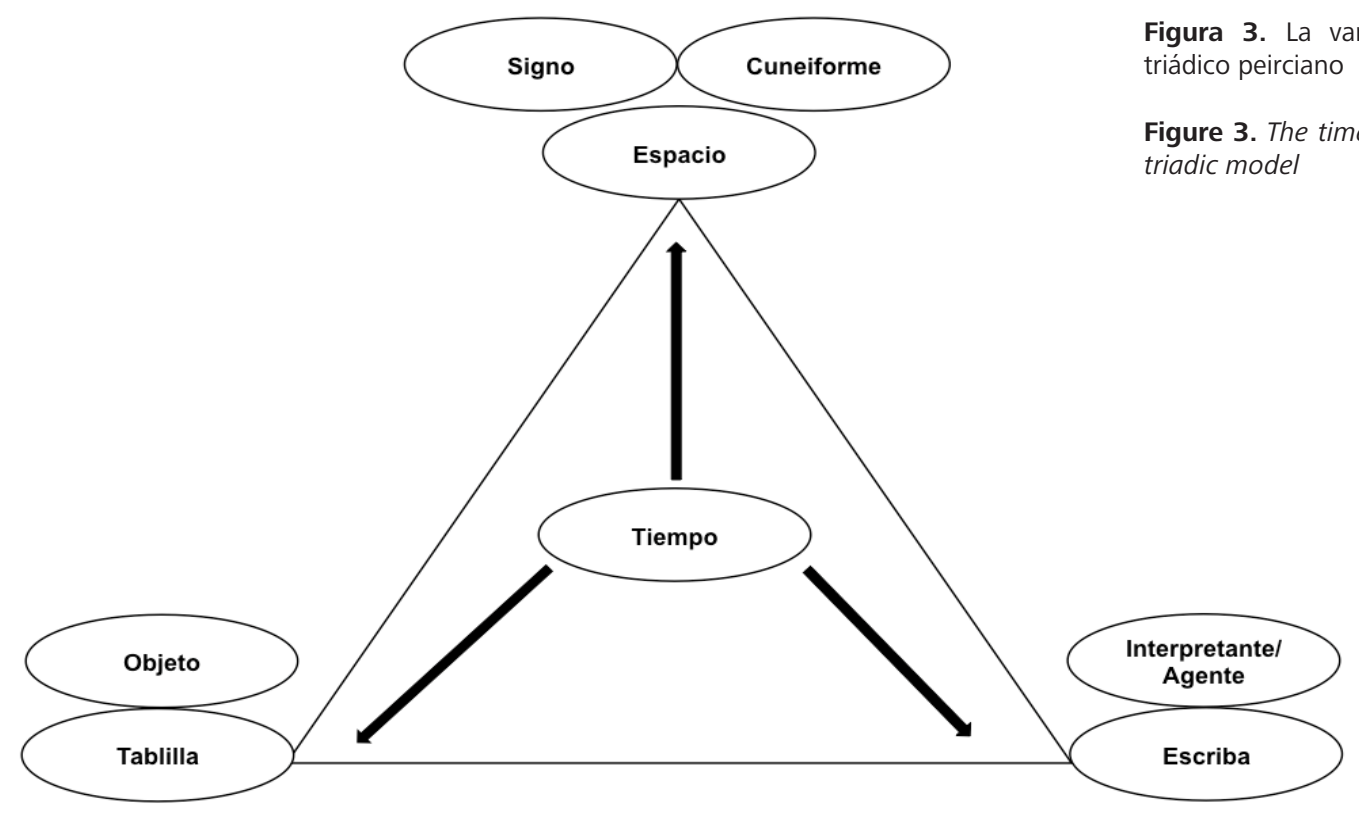

\section{0. $\mathrm{mu} . .$. ("IS 9") Año... (9 de Ibbi-Su'en)}

De alguna manera, el paisaje cosmológico se reactualizaba y, por lo tanto, funcionaba de manera activa a través de los agentes más importantes para su reproducción: los muertos (Porter 2007-2008: 200). El cadáver se presentaba como un nexo en las relaciones sociales, un punto de conexión entre el mundo de los vivos y el otro, y, de este modo, en tanto "ancestros, los muertos configuran las relaciones entre los vivos" (Porter 2007-2008: 202).

Asimismo, la celebración del ritual de ofrenda funeraria no sólo señaló la articulación del mundo de los vivos y el Inframundo -este último como espejo del anterior-, sino también la necesidad de apaciguar el carácter vengativo de los muertos. Los textos literarios señalan cómo la alimentación y el cuidado de los muertos tuvieron como objetivos principales constreñir los aspectos negativos de aquellos que estaban en el Más Allá (Cabrera 2017).

Por otro lado, la reutilización del espacio sagrado vinculado a los enterratorios de Ur durante la época neosumeria-donde se ubicaban las tumbas reales del PD III-y las construcciones adyacentes de los mausoleos de reyes como Šulgi y Amar-Su'ena implicaron la cimentación material y monumentalizada de los gobernantes de Ur III de su poder político, sostenido discursivamente por el uso de los himnos reales (Laneri 2008: 206), y la delimitación de un tipo de "ideología funeraria" (Porter 2002), cuyo correlato fue la jerarquización del mundo social y la delimitación topográfica del Inframundo en los textos literarios (Katz 2003).

La tríada espacio/tablilla/agente, que mencionábamos al comienzo de este apartado, puede articularse en paralelo al tipo de estructuras funerarias con las que contamos para discutir los paisajes funerarios. En principio, los textos administrativos son fundamentales para entender el rol que tuvieron determinadas construcciones mortuorias que se realizaron para evocar a los muertos de la elite en ciertas festividades y, así, se habría producido la imposición de un calendario ritual (ver aparato siguiente).

No obstante, todavía no podemos determinar a qué estructura específica se hace referencia a través de los textos administrativos con los vocablos ki-mah ("tumba" o "cementerio"), ki-a-nag ("capilla funeraria") y a-buum ("tubo para verter libaciones"), aunque para Ur III, sobre todo por medio del estudio de la documentación administrativa se puede entender algunas de las funciones que poseían.

De acuerdo al planeamiento urbano de Ur, capital del estado durante el período neo-sumerio, los mausoleos respectivos de Šulgi y su sucesor Amar-Su'ena se ubicaron en las cercanías de los enterratorios del PD IIIb, estableciéndose una continuidad en la apropiación del espacio. Por otra parte, la mención de las capillas funerarias en la documentación administrativa de Ur III en tanto centros acaparadores de ofrendas para los difuntos ( $y$, por consiguiente, receptores en la cadena de circulación económica de bienes) las colocaba como sitios de competencia con los templos de los dioses. En la parte noroeste del sitio predomina la estructura del templo de Nanna, el dios lunar y patrono de Ur, mientras que en la sureste se halla el E-hursaĝ, una construcción que se pensaba que habría funcionado como palacio real, aunque luego fue asociada con el templo del dios central del panteón, Enlil, cuya residencia más importante estaba en Nippur. Esta última hipótesis permanece todavía en discusión, si bien se han hallado ladrillos de fundación que mencionan tanto a Ur-Namma como a Šulgi en tanto constructores y, además, que vinculan el 
santuario con el culto de Enlil.

La planificación de un paisaje funerario durante Ur III se logró a través de la edificación de los denominados mausoleos de los reyes en las cercanías no sólo de las tumbas reales, sino también muy próximos a los templos del dios tutelar del panteón mesopotámico, así como también de la deidad patrona del sitio de Ur. Asimismo, se estableció un parentesco divino por medio de la deificación de los gobernantes neo-sumerios -como se evidencia en la himnología real de la época, donde los reyes se identificaban con el dios pastor Dumuzi, como esposos de Inanna, hermanos de Gilgameš, etc.- y, también, por la edificación de sitios destinados al culto real en las proximidades de los templos de las divinidades más importantes.

En conjunción a la información suministrada por las estructuras de enterramiento, los textos administrativos aportan datos específicos sobre el funcionamiento de las capillas funerarias, donde se menciona de qué manera y cuándo se realizaba el culto mortuorio de los reyes de Ur III. Dependiendo del archivo provincial en consideración, por ejemplo, los textos de PuzrišDagān aluden a los animales que se utilizaban como víctimas sacrificiales en ceremonias específicas o los de Ĝirsu, que refieren a las ofrendas en cereales o textiles destinadas para los difuntos. Sin embargo, debe tenerse en cuenta que, dado que estamos trabajando con textos administrativos, los mismos recogen información del conjunto de la organización estatal en sus múltiples dimensiones, de la que la funeraria era una más. Además, el ordenamiento del espacio y la delimitación de temporalidades vinculadas al mundo de los muertos estuvo mediada por los escribas en tanto agentes del estado y, por consiguiente, las tablillas en tanto artefactos fueron primordiales en la circulación y plasmación de la ideología estatal.

\section{Más allá de la escritura, más acá de la materialidad (v): la temporalidad de los paisajes funerarios}

Como último punto, proponemos un abordaje de los paisajes funerarios desde su temporalidad, la cual se presenta como un palimpsesto. Tal como planteábamos a propósito de la composición del signo lingüístico, el proceso de semiosis en el cual se encuentra inmerso este mismo apunta hacia atrás (pasado) en un objeto y hacia delante (futuro) en un interpretante. En base al modelo semiótico peirciano, hemos planteado el vínculo que se articula entre objeto (artefacto) o tablilla, espacio (definido a partir de la materialidad que supone la escritura cuneiforme) y agente/interpretante, es decir, el escriba. En relación a este último punto, podríamos incorporar, teniendo en cuenta que el signo lingüísitico en su proceso infito de semiosis mira hacia el futuro al interpretante, al campo académico, el cual (re-)lee y (re-)construye el pasado a partir de lo que podríamos denominar "aporías del tiempo" (Figura 3).

La aporía temporal señala las contradicciones que existen en la narración misma que contienen las tablillas cuneiformes; en el caso que analizamos, los textos administrativos, puesto que, si bien se los ha pensado como textos desprovistos de una connatación ideológica por ser más bien descriptivos (a diferencia de los textos literarios), creemos que están atravesados por el sistema de pensamiento de la época. En efecto, de acuerdo a Paul Ricoeur en Temps et récit (1983) -donde el autor recupera las discusiones de Artistóteles y San Agustínexistiría un tiempo del alma y otro tiempo referido al mundo. Tal como afirma el autor,

"[es importante] para una teoría narrativa dejar libre tanto el acceso al problema del tiempo: tanto desde el lado del espíritu como del mundo. La aporía de la temporalidad, a la que responde la operación narrativa de varias maneras, consiste precisamente en la dificultad de mantener los dos extremos de la cadena: el tiempo del alma y el tiempo del mundo" (Ricoeur 1983: 22).

Por consiguiente, existirían dos temporalidades convivientes de acuerdo a la anterior perspectiva, que también Martin Heidegger ya había señalado en Sein und Zeit (1967 [1927]), en tanto "tiempo privado" y "tiempo público", el filósofo había discutido la "cosificación" de ese tiempo o lo que se denomina "vulgarmente como el tiempo". Siguiendo su análisis,

"[p]or lo tanto, si el tiempo del mundo pertenece a la temporización (Zeitigung) de la temporalidad (Zeitlichkeit), entonces no puede ser "subjetivamente" volatilizado ni "reificado" en una mala "objetivación". Ambos sólo se evitan debido a una visión clara, y no simplemente sobre la base de una vacilación incierta entre las dos posibilidades, cuando puede entenderse cómo la existencia cotidiana, desde su comprensión inmediata del tiempo, capta teóricamente el "tiempo" y hasta qué punto este concepto del tiempo y su regla obstruyen la posibilidad para entender lo que se quiere decir desde el tiempo original, es decir, como temporalidad. La preocupación diaria que se da a sí misma tiempo encuentra "el tiempo" en los entes intramundanos, que "en el tiempo" se encuentra. Por lo tanto, la elucidación de la génesis del concepto vulgar del tiempo (vulgären Zeitbegriffes) debe tomar su punto de partida en la intratemporalidad (Innerzeitigkeit)" (Heidegger 1967 [1927]: §80, 420).

De acuerdo a Heidegger, el tiempo se comprondría de tres "éxtasis": el pasado, el presente y el futuro. En esta tripartición, el pasado se proyecta como construcción de posibilidad del pasado y en tanto potencialidad hacia el futuro, de la misma manera que el signo lingüístico se vinculaba con un objeto en tanto pasado y con un futuro en tanto interpretante. 
A partir de esta premisa, la reconstrucción y la habitación de todo paisaje funerario implicaba la articulación de espacialidades y temporalidades que hemos planteado a partir del análisis de los textos administrativos de Ur III. De este modo, la articulación de un "tiempo público" con otro "tiempo privado" subrayó la imposición de un calendario ceremonial (Sallaberger 1993), en el que los muertos de la elite, en tanto miembros de la clase dirigente, se convirtieron en divinidades que demandaron un culto periódico en un sitio específico, el ki-a-naĝ o capilla funeraria. La muerte puso de relieve, asimismo, la delimitación de un nuevo tipo de personhood, dado que los reyes muertos se convirtieron en divinidades que demandaron de la contribución periódica de bienes. La transformación en deidades asociadas al panteón oficial también implicó no sólo la ejecución periódica de rituales evocativas, sino también aceptar el nuevo estatus de los monarcas muertos y su deificación.

La emergencia de un sector de la elite asociado al palacio y ya no al templo durante el PD IIIb y su consolidación política durante Ur III tuvo su correlato en la edificación del paisaje funerario, del cual se la variable temporal fue esencial, ya que se impuso un calendario, cuyos meses tenían los nombres de los monarcas difuntos. Dicho fenómeno fue exclusivo de la Baja Mesopotamia, puesto que tanto en Siria como en la Alta Mesopotamia no hubo miembros de la elite diferenciados a través de sus nombres y asociados a festividades cúlticas, sino que más bien existió una "coorporación de ancestros" (Porter 2002).

Además, la centralización política de la administración y la reorganización del estado durante el reinado de Šulgi, sobre todo luego de las campañas de conquista e incorporación de nuevos territorios, también tuvo como correlato la imposición, desde el centro hegemónico de Ur, de una visión de mundo y, también, de un tiempo público asociado tanto a la celebración de rituales como a la recolección de tributos necesarios para el mantenimiento del estado.

\section{A modo de cierre: más allá de la escritura, más acá de la materialidad}

La cimentación de los paisajes funerarios en Mesopotamia durante Ur III se sustentó a partir de la siguiente materialidad triádica: ofrenda funeraria/ muerto (cuerpo)/lugar conmemorativo (Figura 4). Esta representación triádica de la dimensión mortuoria tuvo en simultáneo una triple finalidad: a) ritual, ya que la ofrenda funeraria puso de relieve la necesidad de perfomances ceremoniales y prácticas de memoria que reactivaban el vínculo con los ancestros (ya sea por una finalidad parental y/o de negociación/legitimación en términos dinásticos); b) política, dado que la edificación de lugares conmemorativos sirvió para depositar a los muertos de la elite dirigente a los que se comenzó a rendir culto $y$, a partir de ello, se agudizó aún más la competencia entre las "grandes organizaciones": templos (clase sacerdotal) y palacios (el rey y la elite dirigente); y c) arquitectónico/monumental, puesto que la diferenciación en el contexto de la ciudad-estado entre una arquitectura de tipo pública (templos y palacios) y otra privada, también se empleó para establecer un hiato entre el mundo doméstico en microescala ( $y$, con ello, de una ritualidad de tipo familiar) y el mundo público en una macroescala, el cual intentaba conseguir imponer un culto oficial/estatal.

El estudio del ki-a-naĝ o capilla funeraria, en tanto expresión material del poder secular encarnado por la institución monárquica, el cual ya se registraba para el PD IIIb y alcanzaría su punto máximo durante Ur III, puede efectuarse a través de un análisis que contemple la perspectiva semiótica peirciana, es decir, teniendo
Paisaje Funerario
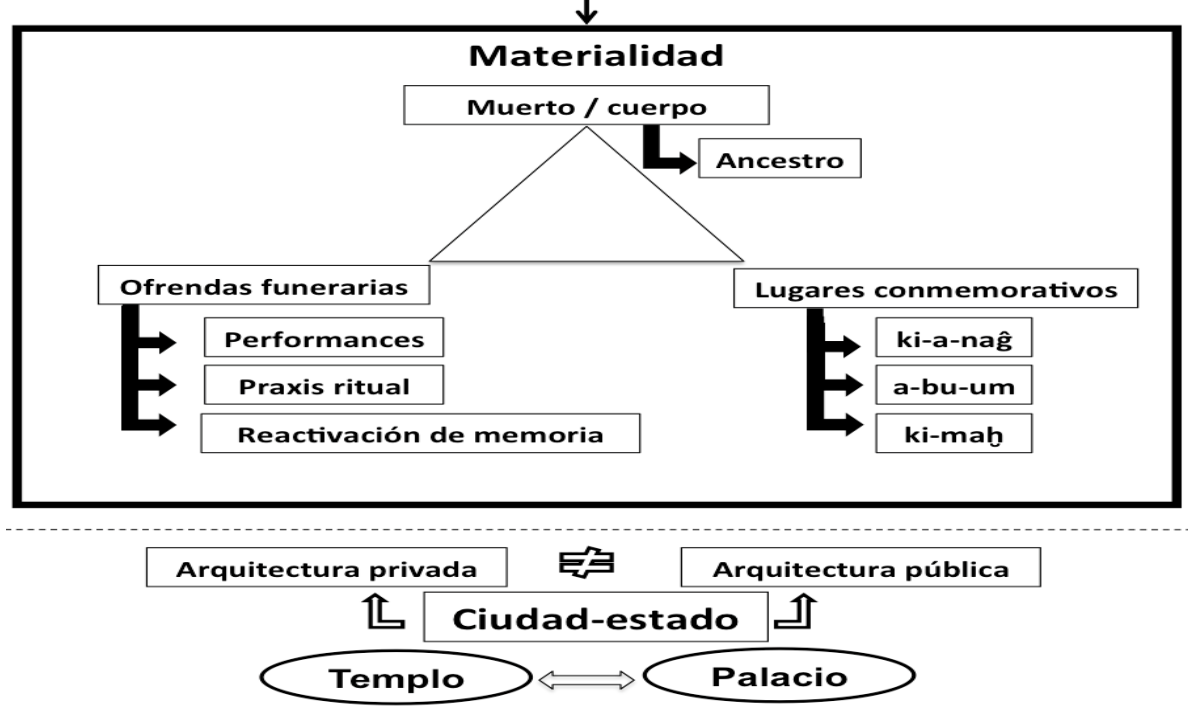

ISSN 1852-060X (impreso) / ISSN 1852-4826 (electrónico)
Figura 4. Paisajes funerarios de Mesopotamia durante Ur III.

Figure 4. Funerary landscapes of Mesopotamia during Ur III. 
en cuenta la tríada escritura cuneiforme/tablilla de arcilla/escriba (agente). Esto resulta central para la reconstrucción de los paisajes funerarios de la Baja Mesopotamia, puesto que los testimonios sobre el ki-anaĝ provenientes del registro epigráfico y contrastados con las estructuras de enterramiento posibilitan la percepción de la materialidad de lo mortuorio a partir de un arco macro que considere una multiplicidad de aproximaciones.

En suma, los textos administrativos fueron centrales en la (re-)construcción de los paisajes funerarios, ya que su análisis permite entender el funcionamiento de las capillas funerarias, en las que habría tenido lugar una ceremonia evocativa de la memoria del muerto en un momento específico del calendario de Ur III. Si la información contenida en los archivos documentales neo-sumerios es contrastada con los datos surgidos del análisis de las estructuras de enterramiento se podría realizar una (re-) construcción de la dimensión funeraria en el marco de los textos administrativos y, por consiguiente, las tablillas contenedoras de esta tipología textual tuvieron una elaboración estandarizada debido a un objetivo político centrado en la materialización y difusión de la ideología estatal. Asimismo, el rol contingente del escriba/agente del estado cooperó en el ordenamiento del espacio y la delitimación de temporalidades conectadas con la construcción de un calendario cultual.

Buenos Aires, 24 de febrero de 2019

\section{Agradecimientos}

Deseo agradecer los comentarios realizados por las/os evaluadoras/es que revisaron el presente artículo, ya que sus aportes sirvieron para enriquecer la propuesta aquí formulada. Asimismo, este trabajo ha sido financiado por un beca doctoral otorgada por el CONICET (Consejo Nacional de Investigaciones Científicas y Técnicas, Argentina) y se enmarca en los siguentes proyectos de investigación: UBACyT (2018-2020) - "Registros funerarios en el Cercano Oriente Antiguo: análisis de estructuras, representaciones e inscripciones" y PIP (2017-2019) - "Arqueología de espacios funerarios: epigrafía y cultura material en el Cercano Oriente Antiguo", ambos dirigidos por la Dra. Liliana M. Manzi.

\section{Bibliografía}

Balke, T., \& Tsouparopoulou, C. (2016). Introduction. En T. Balke \& C. Tsouparopoulou (Eds.). Materiality of Writing in Early Mesopotamia (Materiale Textkulturen 13) (pp. 1-10). Berlin / New York: Walter de Gruyter.

Barrett, J.C. (1999). The Mythical Landscapes of the British Iron Age. En W. Ashmore \& B. Knapp (Eds.). Archaeologies of Landscape. Contemporary Perspectives (pp. 253-265). Oxford: Blackwell Publishers.

Bartash, V. (2014). E2-mi2 - 'Women's Quarters': the Earliest Written Evidence. En F. Buccellati, T. Helms \& A. Tamm
(Eds.). House and Household Economies in 3rd Millennium B.C.E. Syro-Mesopotamia (British Archaeological Reports/ International Series 2682) (pp. 9-20). Oxford: Archaeopress .

(BDTNS): Molina, M. (Ed.). (2002-). Base de Datos de Textos Neosumerios. Recuperado de: http://bdts.filol.csic.es Bourdieu, P. (1977). Outline of a Theory of Practice, traducción de Richard Nice (Cambridge Studies in Social and Cultural Anthropology 16). Cambridge: Cambridge University Press.

Cabrera, R. (2016). Reconstruyendo "espacios materiales" a partir de tablillas cuneiformes. La frecuencia terminológica del vocablo ki-mah (tumba) en textos administrativos de Ur III. En: Actas del XIX Congreso Nacional de Arqueología Argentina, 8-12 de agosto de 2016 (Serie Monográfica y Didáctica 54) (pp. 3103-3106). San Miguel de Tucumán: Facultad de Ciencias Naturales e Instituto Miguel Lillo, Universidad Nacional de Tucumán.

Cabrera, R. (2017). La inter-textualidad y la inter-materialidad de los objetos. La "ofrenda funeraria" en la tensión entre cultura material y evidencia epigráfica entre el Dinástico Temprano IIIB y la época neo-sumeria (Baja Mesopotamia, c. 2600-2100 a.C.). Sociedades precapitalistas. Revista de Historia Social, 7(1), e020. https://doi.org/10.24215/22505121e020.

Cabrera, R., \& Calomino, E.A. (2016). Inventando muertos: paisajes funerarios y prácticas de memoria en la Baja Mesopotamia entre los períodos Dinástico Temprano IIIB y neo-sumerio. En V. Aldazábal, L. Amor, M. Díaz, R. Flammini, N. Franco \& B. Matossian (Comps.). Territorios, Memorias e Identidades. Actas de las IV Jornadas Multidisciplinarias, Buenos Aires, 4 al 5 de noviembre de 2015 (pp. 107-124). Buenos Aires: Latingráfica / Instituto Multidisciplinario de Historia y Ciencias Humanas, CONICET.

(CAD): Biggs, R.D., Brinkman J.A., Civil, M., Farber, W., Gelb, I.J., Landsberger, B., Oppenheim, A.L., Reiner, E., Roth, M., \& Stolper, M. (Eds.) (1956-2010). The Assyrian Dictionary of the Oriental Institute of the University of Chicago. 21 vols. Chicago: The Oriental Institute of the University of Chicago.

Cohen, A. (2005). Death Rituals, Ideology, and the Development of Early Mesopotamian Kingship: Toward a New Understanding of Iraq's Royal Cementery of Ur (Ancient Magic and Divination 7). Leiden: Brill.

Cohen, M.E. (1993). The Cultic Calendars of the Ancient Near East. Bethesda: CDL Press.

Garfinkle, S.J. (2013). Ancient Near Eastern City-States. En P. Figiber Bang \& W. Scheidel (Eds.). The Oxford Handbook of the State in the Ancient Near East and Mediterranean (pp. 94119). Oxford / New York: Oxford University Press.

Gibson, J.J. (1979). The Ecological Approach to Visual Perception: Boston: Houghton Mifflin.

González Ruibal, A. (2012). Hacia otra arqueología: diez propuestas. Complutum, 23(2), 103-116.

Gosden, C. (1994). Social Being and Time. Oxford: Blackwell Publishers.

Heidegger, M. (1967 [1927]). Sein und Zeit. Tübingen: Max Niemeyer Verlag.

Heidegger, M. (1994). Construir, habitar, pensar. En Conferencias 
y artículos de Martin

Heidegger, traducción de Eustaquio Barjau (pp. 127-142). Barcelona: Ediciones del Serbal.

Ingold, T. (2007). Materials against Materiality. Archaeological Dialogues, 14(1), 1-16

Jagersma, B. (2007). The Calendar of the Funerary Cult in Ancient Lagash. Bibliotheca Orientalis, 64: 289-307.

Katz, D. (2003). The Image of the Netherworld in the Sumerian Sources. Bethesda: CDL Press.

Keane, W. (2005). Signs Are Not the Garb of Meaning: On the Social Analysis of Material Things. En D. Miller (Ed.). Materiality (pp. 182-205). Durham / London: Duke University Press.

Kobayashi, T. (1985). The ki-a-nag of Enentarzi. Orient, 21, 10-30

Laneri, N. (2008). Texts in Context: Praxis and Power of Funerary Rituals among Elites in Ancient Mesopotamia. En L. Fogelin (Ed.). Religion, Archaeology, and the Material World (pp. 196215). Carbondale: Center for Archaeological Investigations, Southern Illinois University Carbondale.

Latour, B. (1991). Nous n'avons jamais été modernes. Essai d'anthropologie symétrique. Paris: La Découverte.

Latour, B. (2005). Reassembling the Social: an Introduction to Actor-Network-Theory. Oxford: Oxford University Press.

Miller, D. (2005). Materiality. An Introduction. En D. Miller (Ed.). Materiality (pp. 1-50). Durham / London: Duke University Press.

Miller, N.F. (2013). Symbols of Fertility and Abundance in the Royal Cemetery at Ur, Iraq. American Journal of Archaeology, $117(1), 127-33$

Molina, M. (1995). Las «reformas» de UruKAgina. Lengua e historia, Antigüedad y Cristianismo XII. Scripta Fulgentina, 5(9/10), 47-80.

Molina, M. (2008). The Corpus of Neo-Sumerian Tablets: an Overview. En S.J. Garfinkle \& J.C. Johnson (Eds.). The Growth of an Early State in Mesopotamia: Studies in Ur III Administration (pp. 19-53) (Biblioteca del Próximo Oriente Antiguo 5). Madrid: Consejo Superior de Investigaciones Científicas.

Molina, M. (2016). Archives and Bookkeeping in Southern Mesopotamia during the Ur III Period. Archéologie de la comptabilité. Culture matérielle des pratiques comptables au Proche-Orient ancien, 8. Recuperado de : http://journals. openedition.org/comptabilites/1980

Piquette, K.E., \& Whitehouse, R.D. (2013). Introduction: Developing an Approach to Writing as Material Practice. En K.E. \& R.D. Whitehouse (Eds.). Writing as Material Practice: Substance, Surface and Medium (pp. 1-13). London: Ubiquity Press.

Porter, A. (2002). Communities in Conflict: Death and the Contest for Social Order in the Euphrates River Valley. Near Eastern Archaeology, 65(3), 156-173.

Porter, A. (2007-2008). Evocative Topography: Experience, Time and Politics in a Landscape of Death. En G. Bartoloni \& M.G. Benedettini (Eds.). Sepolti tra i vivi. Evidenza ed interpretazione di contesti funerari in abitato. Atti del Convegno Internazionale,
Roma, 26-29 Aprile 2006 (Scienze dell'Antichità 14/1) (pp. 7180). Roma: Quasar.

Preucel, R.W. (2006). Archaeological Semiotics. Malden / Oxford: Blackwell.

Ricoeur, P. (1983). Temps et récit I: L'intrigue et le récit historique. Paris: Éditions du Seuil.

Sallaberger, W. (1993). Der kultische Kalender der Ur-III-Zeit (Untersuchungen zur Assyriologie und Vorderasiatischen Archäologie 7/1). Berlin / New York: Walter de Gruyter.

Sallaberger, W., \& Schrakamp, I. (2015). History \& Philology (Associated Regional Chronologies for the Ancient Near East and the Eastern Mediterranean 3). Turnhout: Brepols.

Saussure, F. (1995 [1916]). Cours de linguistique générale. Paris: Payot.

Sharlach, T. (2004). Provincial Taxation and the Ur III State. Leiden / Boston, MA: Brill Styx.

Steinkeller, P. (2013). Corvée Labor in Ur III Times. En S.J. Garfinkle \& M. Molina (Eds.). From the 21st Century B.C. to the 21st Century A.D. Proceedings of the International Conference on Sumerian Studies Held in Madrid 22-24 July 2010.: (pp. 347424). Winona Lake, IN: Eisenbrauns.

Tilley, C. (1994). A Phenomenology of Landscape: Places, Paths and Monuments. Oxford / Providence: Berg.

Tilley, C. (2006). Objectification. En C. Tilley, W. Keane, S. Küchler, M. Rowlands \& P. Spyer (Eds.). Handbook of Material Culture (pp. 60-73). London: Sage Publications Ltd.

Tsouparopoulou, C. (2015). Spreading the Royal Word: The (Im)Materiality of Communication in Early Mesopotamia. En S. Enderwitz \& R. Sauer (Eds.). Communication and Materiality in Pre-Modern Societies (Materiale Textkulturen 8) (pp. 7-23). Berlin / New York: Walter de Gruyter

Tsouparopoulou, C. (2016). Deconstructing Textuality, Reconstructing Materiality. En T. Balke \& C. Tsouparopoulou (Eds.). Materiality of Writing in Early Mesopotamia, editado por (Materiale Textkulturen 13) (pp. 257-275). Berlin / New York: Walter de Gruyter.

Vaquer, J.M. (2012). Apuntes para una semiótica de la materialidad. Comechingonia, 16(1), 13-29.

Vaquer, J.M. (2014). El Tiempo de los Ancestros. Temporalidad, Ideología Semiótica y Poder en Cruz Vinto (Norte de Lípez, Bolivia) durante el Periodo de Desarrollos Regionales Tardío (1200 - 1450 DC). Arqueología Sudamericana, 6(1/2), 57-86.

Veldhuis, N. (2011). Levels of Literacy. En K. Radner \& E. Robson (Eds.). Oxford Handbook of Cuneiform Culture (pp. 68-89). Oxford: Oxford University Press.

Woolley, L. (1934). The Royal Cemetery. A report on the Predynastic and Sargonic Graves Excavated between 1926 y 1931 (Ur Excavations 2). London / Philadelphia: Trustees of the British Museum and of the Museum of University of Pennsylvania.

Woolley, L. (1974). The Building of the Third Dynasty (Ur Excavations 6). London / Philadelphia: Trustees of the British Museum and of the Museum of University of Pennsylvania. 